\title{
Response Surface Optimization for Antioxidant Extraction from Jackfruit (Artocarpus heterophyllus Lam.) Seed and Pulp
}

\author{
M. A. Hossain, M. S. S. Evan, M. S. Moazzem, M. Roy, W. Zzaman* \\ Department of Food Engineering and Tea Technology, Shahjalal University of Science and \\ Technology, Sylhet-3114, Bangladesh
}

Received 12 December 2019, accepted in final revised form 11 April 2020

\begin{abstract}
The maximum yield of antioxidant activity of freeze-dried jackfruit seeds and pulps was optimized in experimental conditions using response surface methodology. Temperature $\left({ }^{\circ} \mathrm{C}\right)$, time $(\mathrm{min})$ and solvent types $(\mathrm{mL})$ were selected as three independent variables. DPPH (2,2-diphenyl-1-picrylhydrazyl radical), TPC (total phenolic content) and FRAP (ferric reducing antioxidant power) were considered for the antioxidant activity. DPPH, TPC and FRAP values of seed ranged from 45-67.90 \%, 2.27-5.42 mg GAE/100 g DM and 63.30$156.39 \mathrm{mg} \mathrm{AAE} / 100 \mathrm{~g} \mathrm{DM}$, respectively while those of pulp were 49-72.14 \%, 2.109-5.02 $\mathrm{mg}$ GAE/100 g DM and 54.90-298.00 mg AAE/100 g DM respectively. The response surface optimization revealed that the optimum conditions for maximum antioxidant activity in seeds were at $65{ }^{\circ} \mathrm{C}, 10 \mathrm{~min}$ and acetone as solvent with $8.76 \% \mathrm{DPPH}, 2.81 \mathrm{mg}$ GAE/100 g DMTPC, $149.99 \mathrm{mg}$ AAE/100 g DM FRAP and 0.99 desirability whereas that of pulp were at $50^{\circ} \mathrm{C}, 10 \mathrm{~min}$ and acetone as solvent with $45.42 \% \mathrm{DPPH}, 3.06 \mathrm{mg}$ GAE/100 g DMTPC, $129.05 \mathrm{mg}$ AAE/100 g DM FRAP and 0.99 desirability. Extraction of antioxidants from jackfruit seed and pulp can be performed more efficiently up to the maximum yield by maintaining the optimum conditions pinpointed in this study.
\end{abstract}

Keywords: Antioxidant activity; Jackfruit; Extraction efficiency; Response surface methodology.

(C) 2020 JSR Publications. ISSN: 2070-0237 (Print); 2070-0245 (Online). All rights reserved. doi: http://dx.doi.org/10.3329/jsr.v12i3.44459

J. Sci. Res. 12 (3), 397-409 (2020)

\section{Introduction}

Jackfruit (Artocarpus heterophyllus Lam.) grows abundantly in the south and northeastern part of the Indian subcontinent. It is widely consumed in South and Southeast Asia and is the national fruit of Bangladesh [1]. Jackfruit has been reported to have a wide range of health promoting bioactive compounds. The antioxidants present in jackfruit have been associated with the improvement of cardiovascular functions, skin, stomach ulcer, digestion, bone, anemia and thyroid gland in human [2]. Various epidemiological studies conducted on human have confirmed that antioxidants extracted from jackfruit can prevent gastric cancer, lung cancer, prostate cancer, coronary heart disease, myocardial

\footnotetext{
*Corresponding author: wahidanft@yahoo.com
} 
infarction, hypertension etc. [3-5]. Both the seeds and pulp of jackfruit are edible. Many investigators have suggested that the seeds of jackfruit are a promising source of natural antioxidants [6-9]. It can also be used as food additives and ingredients. Jackfruit seeds contain lignans, isoflavones, saponins and all phytonutrients [10]. The seeds of jackfruit are usually consumed after boiling or roasting. Flours are also produced from jackfruit seeds by grinding roasted dried seeds [11]. Jackfruit seeds are a good source of starch (22 $\%)$ and dietary fiber (3.19\%) [12]. Because of its antibacterial and antimicrobial properties, nanoparticles extracted from jackfruit seeds can be used as a therapeutic agent to prevent food poisoning caused by food-borne pathogens [13]. Jackfruit pulp contains vitamin $\mathrm{A}$, vitamin $\mathrm{C}$, thiamin, riboflavin, calcium, potassium, iron, sodium, zinc, and niacin among many other nutrients [14]. The pulp of jackfruit has a low caloric content. $100 \mathrm{~g}$ of jackfruit pulp contains only 94 calories [15]. Jackfruit pulp is a rich source of potassium which helps to lower blood pressure [16]. The pulp contains phytonutrients like lignans, isoflavones and saponins that have wide ranging health benefits [17]. Jackfruit pulps are now industrially being used to process ice cream, jam, jelly, alcoholic beverages, nectars or fruit powders [18]. Some jackfruit-based food products such as chips, noodles, canned jackfruit, jackfruit nectar and jackfruit flavored drinks are currently available in market $[2,19,20]$. Jackfruit powder has shown a lot of potential to be used as a raw ingredient in pasta, instant soup, bakery products, dairy products and baby foods $[21,22]$. However, the industrial use of jackfruit has not been fully diversified yet. As fresh fruits can deteriorate easily, seed and pulp flour made from jackfruit can be a viable alternative food ingredient [23]. The non-edible part of jackfruit has been used to make biodegradable packaging films [7,24]. A new trend has peaked in the recent years in the search of natural sources of antioxidants, especially from plant origins [25,26]. Antioxidants are considered as compounds that can delay, retard or prevent the oxidation process [27]. The natural antioxidants found in fruits and vegetables have recently gained immense interest among food scientists, nutritionists and consumers because of their ability to reduce risk of chronic diseases [28]. Antioxidants extracted from the seeds and pulps of jackfruit have been reported to prevent or improve a lot of problems and diseases related to human health $[1,2,29]$. Numerous literatures are available on jackfruit-based food products and the health benefits of jackfruit [1,2,7,14,30-32]. In a traditional method of optimization, also known as "one factor at a time" optimization, an individual factor is changed continuously while keeping all other remaining factors constant, until the best value of the response can be selected. This traditional technique is laborious and could be erroneous, because it does not take into account the interactions between factors. This limitation can easily be solved using a specific design of experiment (DOE) [33]. Although a very few studies have discussed the antioxidant activity of jackfruit leaf extracts [34], no study has been conducted till date on the optimization of experimental conditions for the maximum yield of antioxidant activity from jackfruit seeds and pulps to the best of our knowledge. Since jackfruit seed and pulp are well-known for their rich antioxidant activity and other therapeutic properties, it may be of great significance if we can develop an optimized antioxidant extraction protocol that can improve the antioxidant 
extraction procedure from jackfruit seed and pulp more efficiently. Keeping these in mind, the current study was conducted to optimize the antioxidant activity of jackfruit seeds and pulps using three different in vitro assay systems, namely radical scavenging activity (DPPH), total phenolic content (TPC) and antioxidant, reducing activity (FRAP) in order to identify the overall optimized antioxidant extraction protocol from jackfruit seeds and pulps.

\section{Materials and Methods}

\subsection{Location of the research}

The current study was conducted during May-August, 2019 in Shahjalal University of Science and Technology, Sylhet 3114, Bangladesh (SUST). The chemical analysis and freeze-drying were carried out in the departmental laboratory of Food Engineering and Tea Technology whereas the antioxidant extraction process was undertaken in the synthetic laboratory of the department of Chemistry.

\subsection{Chemicals used}

Ethanol $\left(\mathrm{C}_{2} \mathrm{H}_{6} \mathrm{O}\right)$, methanol $\left(\mathrm{C}_{3} \mathrm{H}_{8} \mathrm{O}\right)$, acetone $\left(\mathrm{C}_{3} \mathrm{H}_{6} \mathrm{O}\right)$, folin-ciocalteu phenol reagent (FCR), 2, 2-diphenyl-1-picrylhydrazyl (DPPH), sodium carbonate $\left(\mathrm{Na}_{2} \mathrm{CO}_{3}\right)$, potassium di-hydro phosphate $\left(\mathrm{KH}_{2} \mathrm{PO}_{4}\right)$, monobasic di-hydrate $\left(\mathrm{NaH}_{2} \mathrm{PO}_{4} .2 \mathrm{H}_{2} \mathrm{O}\right)$, potassium ferricyanide $\left(\mathrm{K}_{3} \mathrm{Fe}(\mathrm{CN})_{6}\right)$, tricholoroacetic acid $\left(\mathrm{C}_{2} \mathrm{HCl}_{3} \mathrm{O}_{2}\right)$, ferric chloride $\left(\mathrm{FeCl}_{3}\right)$ and other necessary chemicals were collected from the laboratory of Food Engineering and Tea Technology.

\subsection{Equipment used}

Freeze dryer (Telstar, Model - LYOQUEST -55), blender (Panasonic, Model - MJM176P), vortex mixer (Digisystem Laboratory, Model - VM-2000), Whatman filter paper (number 4), refrigerator, UV spectrophotometer (PG Instruments Ltd, Model - T60 U), hot water bath (NE2-9D Bennett Scientific) and incubator (AAH 26016U) were used to perform the experiments.

\subsection{Preparation of materials}

'Gala' variety of jackfruit was used in this study as the chemical composition of jackfruit depends upon the type of cultivar [10]. Mature and ripe 'gala' jackfruits were collected from the germplasm center of Bangladesh Agricultural University. They were brought to the laboratory of Food Engineering and Tea Technology of SUST. Then jackfruits were cleaned thoroughly using tap water. The jackfruits were broken open with hands and the bulbs were collected. Then the seeds were separated from the pulp of jackfruit bulbs. Immediately afterwards, the seeds and pulps were subjected to freeze drying at $-49\left({ }^{\circ} \mathrm{C}\right)$ and 125 psi pressure for 28 and $18 \mathrm{~h}$, respectively, using Telstar freeze drier (Model LYOQUEST -55). 


\subsection{Procedure for extraction}

Each of the extraction procedure was carried out using $0.5 \mathrm{~g}$ of freeze-dried powder of jackfruit seed and pulp. For the extraction, a $2^{3}$ full factorial screening design was carried out with center points where three independent variables were designated as $A_{1}$ (temperature in ${ }^{\circ} \mathrm{C}$ ), $\mathrm{A}_{2}$ (time in min) $\mathrm{A}_{3}$ (solvent types as $\mathrm{mL} / \mathrm{g} \mathrm{DM}$ (Dry Matter)). The samples were well-vortexed before the extraction as well as afterwards. The samples were ensured to be airtight so that prevent evaporation losses could be prevented during the extraction procedure. The samples were filtered at the end of each extraction using Whatman filter paper (number 4). The DPPH radical scavenging property, total phenolic content (TPC) and ferric reducing antioxidant activity (FRAP) of the extracts were determined using the filtrates. The yield calculation was done by precisely measuring the extracts' yield after drying by using four decimal electronic balances. Then they were expressed as percentages.

\subsection{DPPH radical scavenging activity}

Slightly modified method of Affandi et al. [33] was used to measure the DPPH radical scavenging activity. About $4 \mathrm{~mL}$ of DPPH solution was mixed in a tube with an aliquot of $1 \mathrm{~mL}$ of the extract. Then the tubes were well-vortexed followed by $30 \mathrm{~min}$ standing in the dark. A UV Spectrophotometer (PG Instruments Ltd, Model - T60 U) was used to measure the absorbance of the mixture at $517 \mathrm{~nm}$. A DPPH radical solution where the aliquot was not added was used as a control. Eq. 1 was used to calculate the DPPH radical scavenging activity.

DPPH radical scavenging effect $(\%)=\left(1-\frac{\text { Absorbance of sample }}{\text { Absorbance control }}\right) \times 100 \%$

\subsection{Total phenolic compounds (TPC)}

The method of Zzaman et al. [35] was used with some modifications to determine the total polar phenolic compound. A $10 \mathrm{~mL}$ flask was used to place approximately $0.5 \mathrm{~mL}$ of the methanolic extracts $0.5 \mathrm{~mL}$ of Folin-ciocalteu phenol reagent was mixed with the solution followed by vigorous shaking for $3 \mathrm{~min}$. $1 \mathrm{~mL}$ of saturated sodium carbonate $\left(\mathrm{NaCO}_{3}\right)$ was added and the mixture was made up to $10 \mathrm{~mL}$ with distilled water. A UV Spectrophotometer (PG Instruments Ltd., Model - T60 U) was used to measure the absorbance of the supernatant of the solution at $725 \mathrm{~nm}$ against a reagent blank. The calibration curve was prepared using GA (gallic acid) as standard. The "mg GAE (GA Equivalent)/100 g of sample" was used to express the results.

\subsection{Ferric reducing antioxidant power (FRAP)}

The modified method of Thaipong et al. [36] was used to measure the ferric reducing antioxidant power of the extracts. An aliquot of $0.3 \mathrm{~mL}$ of ethanolic extract was added and vortexed with $0.85 \mathrm{~mL}$ of $0.2 \mathrm{M}$ phosphate buffer ( $\mathrm{pH} 6.6$ ) and $0.85 \mathrm{~mL}$ of $1 \%$ potassium 
ferricyanide. Then the mixture was incubated at $50{ }^{\circ} \mathrm{C}$ for $20 \mathrm{~min}$. Afterwards, $0.85 \mathrm{~mL}$ of $10 \%$ trichloroacetic acid was added and well-vortexed with the mixture. $2.85 \mathrm{~mL}$ of distilled water and $0.57 \mathrm{~mL}$ of $1 \% \mathrm{FeCl}_{3}$ were added finally to the mixture followed by incubating at $25^{\circ} \mathrm{C}$ for $30 \mathrm{~min}$. A UV Spectrophotometer (PG Instruments Ltd., Model T60 U) was used to measure the absorbance at $700 \mathrm{~nm}$ after the second incubation. A parallel blank was prepared using distilled water instead of the aliquot. A serial aqueous dilution of stock solution was carried out to prepare the standard ascorbic acid. The absorbance was then fitted against its corresponding standard ascorbic solutions to prepare the standard curves. The "mg AAE (Ascorbic Acid Equivalent)/100g DM (Dry Matter)" was used to express the results

\subsection{Variable identification and model fitting}

Temperature $\left({ }^{\circ} \mathrm{C}\right)$, time $(\min )$ and solvent types $(\mathrm{mL} / \mathrm{g} \mathrm{DM})$ were the three most promising variables and they were selected because of their relevance. $80 \%$ level of concentration (solvent: water $=4: 1$ ) was ensured for the use of the solvent. The screening test along with the optimization process were conducted using a full factorial experimental design $\left(2^{3}\right)$ maintaining three replications at the center. The coded values of in the independent variables and their corresponding responses were used to generate each of the multiple regression equations. The independent variables' influences towards the responses were determined using the comparative values of these multiple regression coefficients. The optimization was carried out using the second - order model. The experimental design and results of the three factorial screening tests both for seed and pulp is given in Table 1 .

Table 1. The ethanolic extraction for jackfruit seed and pulp describing a full $2^{3}$ factorial experimental design along with corresponding responses.

\begin{tabular}{cccc}
\hline Run & $\mathrm{A}_{1}$ (Temperature in $\left.{ }^{\circ} \mathrm{C}\right)$ & $\mathrm{A}_{2}$ (Time in min) & $\mathrm{A}_{3}$ (Solvent types in $\left.\mathrm{mL} / \mathrm{g} \mathrm{DM}\right)$ \\
\hline 1 & 50 & 10 & Methanol \\
2 & 50 & 30 & Methanol \\
3 & 50 & 20 & Ethanol \\
4 & 50 & 20 & Acetone \\
5 & 65 & 10 & Ethanol \\
6 & 65 & 30 & Ethanol \\
7 & 65 & 20 & Methanol \\
8 & 65 & 20 & Methanol \\
9 & 65 & 20 & Methanol \\
10 & 65 & 10 & Acetone \\
11 & 65 & 30 & Acetone \\
12 & 80 & 20 & Ethanol \\
13 & 80 & 10 & Methanol \\
14 & 80 & 30 & Methanol \\
15 & 80 & 20 & Acetone \\
\hline
\end{tabular}




\subsection{Statistical analysis}

To conduct the experimental design and the statistical analysis, well-known software package $\mathrm{R}$ (version 2.14.1) was used in this study. All the tests of statistical significance were based on. The total criterion of error for all the tests of statistical significance was $95 \%$ confidence level. The least-square method was used to analyze the data by multiple regressions. The full factorial $\left(2^{3}\right)$ experimental design was carried out using first-order polynomials with three runs at the center. Only the significant $(p \leq 0.05)$ variables of the screening test were considered for later experiments. The first-order polynomial equation has been expressed by Eq. 2:

$$
Y_{r}=a_{o}+\sum_{i=1}^{n} a_{i} X_{i}+\sum_{i \neq j=1}^{n} a_{i j} X_{i} X_{j}
$$

But we were not able to match the first-order model enough based on the experimental trials. So, we used the Box-Behnken design to fit the experimental data with the secondorder polynomial equations as expressed by Eq. 3:

$$
Y_{r}=a_{o}+\sum_{i=1}^{n} a_{i} X_{i}+\sum_{i=1}^{n} a_{i i} X_{i}^{2}+\sum_{i \neq j=1}^{n} a_{i j} X_{i} X_{j}
$$

Both in Eq. (2) and Eq. (3), $Y_{r}$ denotes the variables' measured responses; $X_{\mathrm{i}}$ and $X_{j}$ denote the levels of independent variables; $a_{o}$ is a constant which denotes the predicted response at the center and $a_{i}, a_{i i}$ and $a_{i j}$ are the linear, quadratic and two factor interactive coefficient of the model, respectively.

\section{Results and Discussion}

The analysis of variance (ANOVA) for response surface linear model of DPPH radical scavenging property, TPC and FRAP for jackfruit seed and pulp against the different run have been represented in Table 2.

Table 2. DPPH radical scavenging property, TPC and FRAP of jackfruit seed and pulp against different runs.

\begin{tabular}{ccccccc}
\hline \multirow{2}{*}{ Run No. } & \multicolumn{2}{c}{ DPPH $(\%)$} & \multicolumn{2}{c}{ TPC $(\mathrm{mg}$ GAE/100 g DM) } & \multicolumn{2}{c}{ FRAP $(\mathrm{mg}$ AAE/100 g DM) } \\
\cline { 2 - 7 } & Seed & Pulp & Seed & Pulp & Seed & Pulp \\
\hline 1 & 49.30 & 45.00 & 3.60 & 4.01 & 298.00 & 152.80 \\
2 & 49.00 & 45.00 & 3.81 & 4.20 & 249.00 & 146.15 \\
3 & 49.50 & 45.57 & 3.49 & 3.90 & 210.50 & 147.44 \\
4 & 49.50 & 45.64 & 3.57 & 3.94 & 207.48 & 149.34 \\
5 & 56.53 & 54.30 & 4.02 & 4.38 & 211.38 & 156.39 \\
6 & 60.70 & 56.43 & 3.93 & 4.23 & 154.40 & 147.82 \\
7 & 59.85 & 55.71 & 3.94 & 4.35 & 175.40 & 145.15 \\
8 & 58.57 & 55.00 & 3.96 & 4.30 & 170.10 & 149.31 \\
9 & 59.28 & 54.22 & 3.91 & 4.30 & 173.25 & 147.37 \\
10 & 56.50 & 56.50 & 2.90 & 3.14 & 152.04 & 107.80 \\
11 & 60.70 & 57.14 & 2.83 & 3.00 & 112.06 & 101.92 \\
12 & 70.71 & 63.60 & 4.79 & 5.15 & 128.86 & 142.80 \\
13 & 72.00 & 66.43 & 5.02 & 5.42 & 134.28 & 150.12 \\
14 & 72.14 & 67.90 & 4.96 & 5.32 & 127.40 & 148.40 \\
15 & 71.40 & 65.70 & 2.10 & 2.27 & 54.90 & 63.30 \\
\hline
\end{tabular}


The predicted values for DPPH radical scavenging property, TPC and FRAP of jackfruit seed and pulp with regression coefficients, the coefficient of determination $\left(\mathrm{R}^{2}\right)$ and lack of fit values for the second order fitted models have been given in Table 3.

Table 3. Predicted values for DPPH radical scavenging property, TPC and FRAP for jackfruit seed and pulp along with regression coefficients, the coefficient of determination $\left(\mathrm{R}^{2}\right)$, lack of fit values for the second order fitted models.

\begin{tabular}{|c|c|c|c|c|c|c|}
\hline \multirow[t]{2}{*}{ Constants } & \multicolumn{2}{|c|}{$\begin{array}{l}\text { Predicted DPPH }(\%) \\
\text { values }\end{array}$} & \multicolumn{2}{|c|}{$\begin{array}{c}\text { Predicted TPC } \\
\text { (mg GAE/100 g DM) } \\
\text { values }\end{array}$} & \multicolumn{2}{|c|}{$\begin{array}{c}\text { Predicted FRAP } \\
\text { (mg AAE } / 100 \text { g DM) } \\
\text { values }\end{array}$} \\
\hline & Seed & Pulp & Seed & Pulp & Seed & Pulp \\
\hline Intercept & 59.71 & 66.68 & 3.94 & 4.34 & 172.92 & 120.61 \\
\hline A: Temperature & 11.12 & 0.19 & 0.30 & 3.25 & -64.94 & -1.14 \\
\hline B: Time & 1.03 & 1.24 & -2.37 & 0.07 & -19.11 & -0.11 \\
\hline $\begin{array}{l}\text { C: Solvent } \\
\text { Types }\end{array}$ & 0.08 & 1.25 & -0.60 & 0.09 & -22.33 & -2.53 \\
\hline $\mathrm{AB}$ & - & 0.01 & -0.06 & -0.03 & 10.53 & 2.14 \\
\hline $\mathrm{AC}$ & - & -0.71 & -0.69 & 0.02 & -17.73 & 3.18 \\
\hline $\mathrm{BC}$ & - & 1.05 & 4.25 & 0.83 & 4.25 & 20.11 \\
\hline $\mathrm{A}^{2}$ & - & -11.94 & 0.24 & 0.04 & 11.11 & 26.51 \\
\hline$B^{2}$ & - & -9.43 & 0.17 & -0.37 & 18.14 & 1.82 \\
\hline $\mathrm{C}^{2}$ & - & 0.62 & -0.69 & -0.06 & -33.59 & 2.55 \\
\hline $\mathrm{R}^{2}$ & 0.9792 & 0.97 & 0.88 & 0.33 & 0.98 & 0.46 \\
\hline Lack of fit test & 0.1634 & 0.1632 & 0.00 & 0.99 & 0.03 & 1.00 \\
\hline
\end{tabular}

\subsection{Response surface analysis of DPPH radical scavenging property}

The DPPH values for jackfruit seed ranged from 49.0-72.14 \% whereas those for pulp were within the range of 45-67.90\% (see Table 2). Fig. 1 illustrates the combined effect of temperature and time on DPPH radical scavenging activity of jackfruit seed and pulp at fixed solvent acetone. Fig. 1 (a) indicates that the DPPH value of seed decreased with an increase in temperature. With the increase of ethanol concentration, the DPPH values of seed decreased gradually. The DPPH values of seed decreased with a decrease in time. It should be noted that temperature did not impact much on the DPPH values of pulp while the values apparently remained simillar to time and temperature. But temperature had a negative impact on the DPPH value of seed. As it can be seen in Figs. 1 (a) and (b), the DPPH value linearly dropped along the time axis. High temperature decreased the dielectric contant of seed but not that of pulp. It implies that compounds contained in the extract were mostly heat sensitive. Although increased temperature might have accelerated chemical degradation of bioactive compounds, high temperature also could have contributed to the decrease of dielectric constant in solvent that could favor the extraction of less polar compounds [35,36]. These results are supported by the reports of Burci et al. [6], Shafiq et al. [30], Thaipong et al. [36], Zhu et al. [37] and are in aggrement with the reports of Zhang et al. [5], Jagtap et al. [16] and Omar et al. [33]. Similar results were also observed by Prasad et al. for Mangifera pajang Kosterm. peels [38]. 


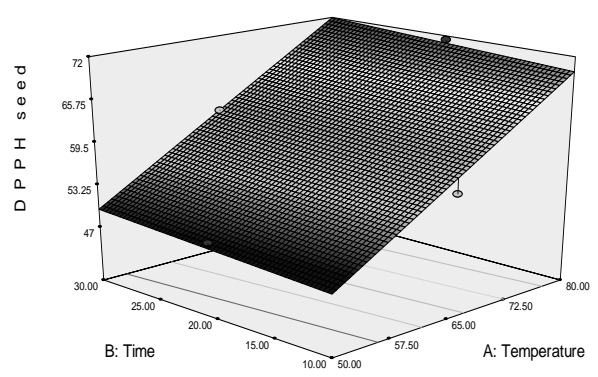

(a)

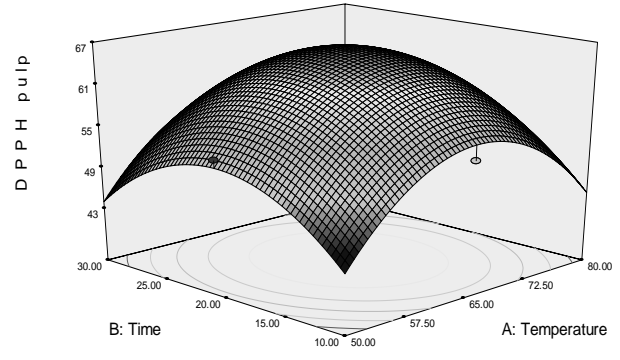

(b)

Fig. 1. The combined effect of temperature and time on DPPH radical scavenging activity (\%) (a) of jackfruit seed and (b) jackfruit pulp demonstrated as response surface plots at fixed solvent acetone.

\subsection{Response surface analysis of TPC}

The TPC values of jackfruit seed varied from 2.109-5.02 mg GAE/100 g DM whereas those of pulp ranged from 2.27-5.42 mg GAE/100 $\mathrm{g}$ DM. The fitness of model and lack of any outliers were confirmed by a standard residual plot. The response surface plots as depicted in Fig. 2 illustrates the combined effect of solvent time and temperature on the response value of TPC for jackfruit seed and pulp. The effect of solvent types on TPC was very similar to that as observed for DPPH. So, similar explanation can be interpreted for the extraction mechanism. As demonstrated in Fig. 2 (a), it is evident that the TPC values of jackfruit seed gradually decreased with the increase in time and temperature. An increase in phenolic solubility may contribute to improved phenolic content extraction through a slight increase in temperature [9,38,39]. Fig. 2(a) indicates that temperature and time had higher negative impact on TPC value of jackfruit seed. But totally opposite phenomenon was observed for TPC value of pulp as evident from Fig. 2 (b). TPC value decreased when temperature reached the highest point. Therefore, temperature and time had totally opposite effect for seed and pulp [40,41]. The phenolic contents (TPC values) of pulp decreased with an increase in temperature. It might have possibly caused by thermal degradation and interference of compound solubility through chemical or enzymatic degradation with other plant compounds [42,43]. These results are consistent with the reports of Burci et al. [6], Shanmugapriya et al. [8] and Shafiq et al. [30]. Similar reports were also mentioned by Zhu et al. [37] and Pavan et al. [44]. 


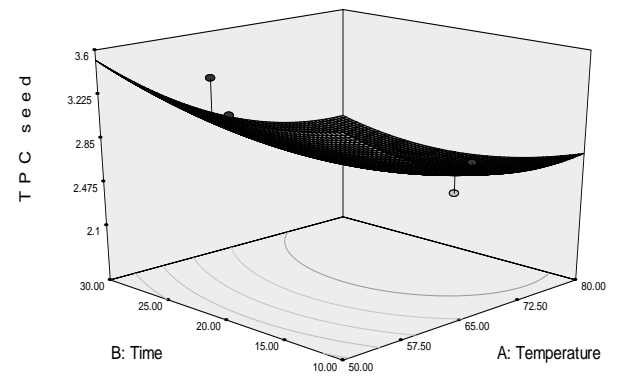

(a)

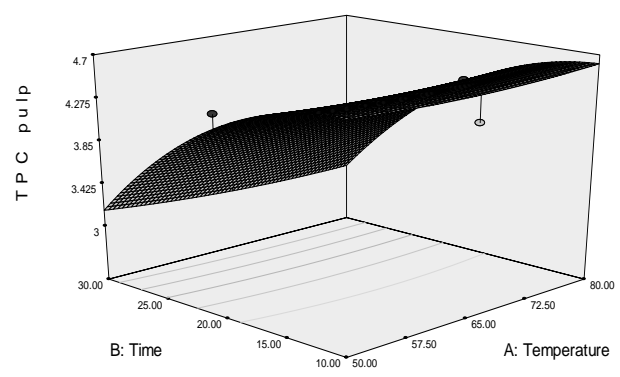

(b)

Fig. 2. The combined eftect of temperature and time on total phenolic content (mg GAE/100 g DM) (a) of jackfruit seed and (b) jackfruit pulp demonstrated as response surface plots at fixed solvent acetone.

\subsection{Response surface analysis of FRAP}

The FRAP values for jackfruit seed were within the range of 63.30-156.39 mg AAE/100 g DM whereas that of pulp varied from 54.90-298.00 mg AAE/100 g DM. Fig. 3 demonstrates the combined effect of temperature and time on the FRAP values of jackfruit seed and pulp. It is evident from Fig. 3 (a) that the FRAP values of seed increaed with an increase in time and a decrese in temperature. But opposite scenario was observed for the FRAP values of jackfruit pulp as illustrated in Fig. 3 (b). FRAP value decreased with a decrease in both temperature and time. These results are supported by the findings as reported by Shanmugapriya et al. [8], Soong and Barlow [9], Loizzo et al. [13], Thaipong et al. [36] and are consistent with the report of Jagtap et al. [16]. Temperature and time might have had a positive impact in the FRAP value of pulp rather than seed. Furthermore, temperature might have affected the polarity of the solvent by changing the dielectric constant, thus significantly influencing the extraction of antioxidants by interacting with the concentration of solvent $[6,35,36]$.

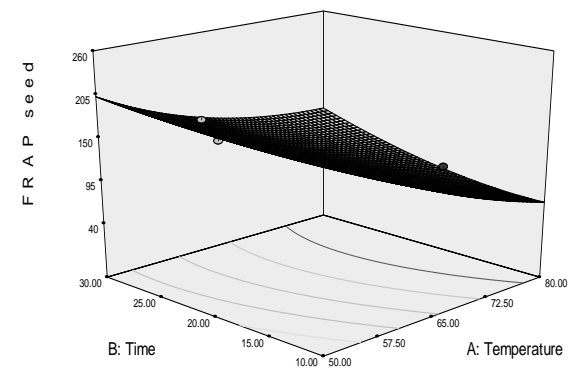

(a)

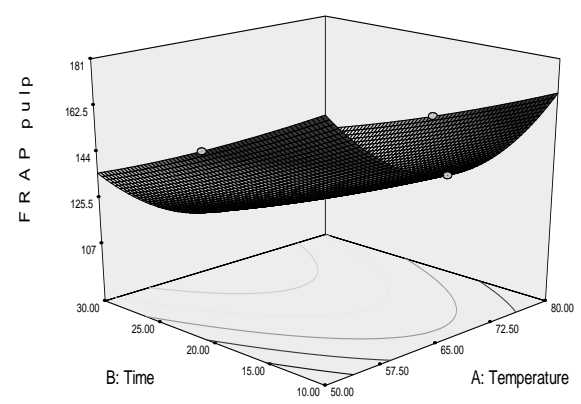

(b)

Fig. 3. The combined effect of temperature and time on ferric reducing antioxidant power (mg AAE/100 g DM) (a) of jackfruit seed and (b) of jackfruit pulp demonstrated as response surface plots at fixed solvent acetone. 


\subsection{Optimum conditions}

In our study, we observed two different sets of optimum conditions when separate optimization was carried out. So, we took both into account by performing simultaneous optimization. Usually, the response surface optimization is performed using two common approaches namely the graphical approach and simultaneous optimization approach. But the lack of atomization has proved the graphical approach to be insufficient. So, we used the simultaneous optimization approach with the function of desirability keeping into consideration. The responses of DPPH, TPC and FRAP were maximized during the optimization process with the same given preferences. We tested the predictive quality of every model and conducted five times replication of all of the responses at the recommended optimum conditions. The influence of three independent variables namely temperature $\left({ }^{\circ} \mathrm{C}\right)$, time $(\mathrm{min})$ and solvent type $(\mathrm{mL} / \mathrm{g} \mathrm{DM})$ towards the DPPH, TPC and FRAP values of the extract was successfully modeled with a second-order polynomial equation as represented by Eq. 3. A weak positive linear effect was observed on the DPPH, TPC and FRAP values of seed and pulp with the concentration of acetone. A significant $(p \leq 0.05)$ interaction effect was found between the quadratic equation with temperature. It implies that the ideal solvent type was acetone. The response surface optimization revealed that the antioxidants from jackfruit seed could be extracted up to their maximum yield at $65{ }^{\circ} \mathrm{C}$ and 10 min using acetone solvent with $8.76 \%$ DPPH, 2.81 mg GAE/100 g DM TPC, $149.99 \mathrm{mg}$ AAE/100 g DM FRAP and 0.99 desirability whereas that of pulp could be obtained at $50{ }^{\circ} \mathrm{C}$ and 10 min using acetone solvent with $45.42 \%$ DPPH, $3.06 \mathrm{mg}$ GAE/100 g DM TPC, $129.05 \mathrm{mg}$ AAE/100 g DM FRAP and 0.99 desirability. When the desirability values are close to 1 , it indicates the ideal condition. We found that the desirability values for jackfruit seed and pulp were 0.99 and 0.99 , respectively. These closer to 1 desirability values indicate that the yield of antioxidant activity from freeze-dried powder of jackfruit seed and pulp could be maximized with the settings described in this study. The results have been given in Table 4.

Table 4. Optimum Conditions for antioxiant extraction from jackfruit seed and pulp along with the maximum yield of antioxidants as measured by DPPH, TPC and FRAP at these conditions considering desirability function.

\begin{tabular}{cccc}
\hline \multirow{2}{*}{ Optimum conditions along with maximum yield } & \multicolumn{2}{c}{ Part of jackfruit } \\
\cline { 3 - 4 } & Temperature $\left({ }^{\circ} \mathrm{C}\right)$ & Seed & Pulp \\
\hline \multirow{2}{*}{ Optimum } & Time $(\mathrm{min})$ & 65.00 & 50.00 \\
conditions & Solvent type & 10.00 & 10.00 \\
& DPPH $(\%)$ & Acetone & Acetone \\
\hline \multirow{2}{*}{ Maximum yield at } & $\mathrm{TPC}(\mathrm{mg} \mathrm{GAE} / 100 \mathrm{~g} \mathrm{DM})$ & 8.76 & 45.42 \\
optimim condition & FRAP(mg AAE $/ 100 \mathrm{~g} \mathrm{DM})$ & 2.81 & 3.06 \\
& Desirability & 149.99 & 129.05 \\
& & 0.99 & 0.99 \\
\hline
\end{tabular}




\section{Conclusion}

In this investigation, we developed a protocol to achieve the maximum yield of antioxidant by optimizing the optimum conditions for antioxidant extraction from jackfruit seed and pulp. Using response surface methodology, the optimum condition for maximum yield of antioxidant activity in seeds was observed when acetone was used as solvent type at $65{ }^{\circ} \mathrm{C}$ and $10 \mathrm{~min}$, showing $8.76 \%$ DPPH, $2.81 \mathrm{mg} \mathrm{GAE} / 100 \mathrm{~g} \mathrm{DM}$ TPC, $149.99 \mathrm{mg}$ AAE/100 g DM FRAP and 0.99 desirability. The optimum condition for maximum yield of antioxidant activity in pulp could be obtained when acetone solvent was used at $50{ }^{\circ} \mathrm{C}$ for $10 \mathrm{~min}$, exhibiting $45.42 \% \mathrm{DPPH}, 3.06 \mathrm{mg} \mathrm{GAE} / 100 \mathrm{~g} \mathrm{DM}$ TPC, $129.05 \mathrm{mg}$ AAE/100 g DM FRAP and 0.99 desirability. Jackfruit seeds and pulp are rich sources of antioxidants that can be used as a natural therapeutic agent in a wide spectrum of health-related problems. Following the protocol developed in this study, the antioxidant extraction procedure from jackfruit seed and pulp may be performed in a more efficient way.

\section{References:}

1. S. B. Swami, N. J. Thakor, P. M. Haldankar, and S. B. Kalse, Comprehensive Rev. Food Sci. Food Safety 11, 565 (2012). https://doi.org/10.1111/j.1541-4337.2012.00210.x

2. R. Ranasinghe, S. D. T. Maduwanthi, and R. Marapana, Int. J. Food Sci. 2019, ID 4327183 (2019).

3. M. Meera, A. Ruckmani, R. Saravanan, and R. L. Prabhu, Nat. Prod. Res. 32, 2740 (2018). https://doi.org/10.1080/14786419.2017.1378200

4. E. Tanjung, Iskandar, Khairina, and A. Biworo, J. Med. Bioeng. 4, 318 (2015). https://doi.org/10.12720/jomb.4.4.318-323

5. M. Shafiq, S. Mehmood, A. Yasmin, S. Khan, N. Khan, and S. Ali, J. Sci. Res. 9, 135 (2017). https://doi.org/10.3329/jsr.v1i1.29665

6. L. M. Burci, C. B. da Silva, M. de Oliveira, L. Dalarmi, S. M. W. Zanin, O. G. Miguel, J. F. G. Dias, and M. D. Miguel, J. Med. Plants Res. 8, 1013 (2015). https://doi.org/10.5897/JMPR2015.5926

7. S. Jancy, R. Shruthy, and R. Preetha, Int. J. Biol. Macromol. 142, 63 (2020). https://doi.org/10.1016/j.ijbiomac.2019.09.066

8. K. Shanmugapriya, P. S. Saravana, H. Payal, S. P. Mohammed, and W. Binnie, Int. J. Pharm. Pharmaceutical Sci. 3, 256 (2011).

9. Y.-Y. Soong and P. J. Barlow, Food Chem. 88, 411 (2004). https://doi.org/10.1016/j.foodchem.2004.02.003

10. J. E. Grimm and M. Steinhaus, J. Agric. Food Chem. 67, 5838 (2019).

11. W. J. Li, Z. G. Fan, Y. Y. Wu, Z. G. Jiang, and R. C. Shi, J. Sci. Food Agric.99, 5283 (2019). https://doi.org/10.1002/jsfa.9729

12. S. Azeez, O. Lasekan, S. Jinap, and R. Sulaiman, J. Food Sci. Technol. 52, 8050 (2015). https://doi.org/10.1007/s13197-015-1900-6

13. M. R. Loizzo, R. Tundis, U. G. Chandrika, A. M. Abeysekera, F. Menichini, and N. G. Frega, J. Food Sci. 75, M291 (2010).

14. D. Qu, C. Liu, M. Jiang, L. Feng, Y. Chen, and J. Han, Molecules 24, 3322 (2019). https://doi.org/10.3390/molecules 24183322

15. S. S. Rana, R. C. Pradhan, and S. Mishra, Food Chem. 278, 185 (2019). https://doi.org/10.1016/j.foodchem.2018.11.032

16. U. B. Jagtap, S. N. Panaskar, and V. A. Bapat, Plant Foods Hum. Nutr. 65, 99 (2010). 
https://doi.org/10.1007/s11130-010-0155-7

17. G. Ruiz-Montanez, A. Burgos-Hernandez, M. Calderon-Santoyo, C. M. Lopez-Saiz, C. A. Velazquez-Contreras, A. Navarro-Ocana, and J. A. Ragazzo-Sanchez, Food Chem. 175, 409 (2015). https://doi.org/10.1016/j.foodchem.2014.11.122

18. D. Govindaraj, M. Rajan, A. A. HatamLeh, and M. A. Munusamy, Int. J. Biol. Macromol.106, 293 (2018). https://doi.org/10.1016/j.ijbiomac.2017.08.017

19. T. Maity, A. S. Bawa, and P. S. Raju, Int. J. Food Sci. 2014, ID 752047 (2014).

20. J. Yi, L. Zhou, J. Bi, Q. Chen, X. Liu, and X. Wu, J. Food Sci. Technol. 53, 1120 (2016). https://doi.org/10.1007/s13197-015-2127-2

21. C. W. Wong and H. H. Tan, J. Food Sci. Technol. 54, 564 (2017). https://doi.org/10.1007/s13197-017-2501-3

22. M. T. Uddin, M. Rukanuzzaman, M. M. Khan, and M. A. Islam, J. Environ. Manage. 90, 3443 (2009). https://doi.org/10.1016/j.jenvman.2009.05.030

23. F. P. Spada, L. M. Zerbeto, G. B. Ragazi, E. M. Gutierrez, M. C. Souza, J. K. Parker, and S. G. Canniatti-Brazaca, J. Agric. Food Chem. 65, 1196 (2017). https://doi.org/10.1021/acs.jafc.6b04836

24. R. F. Santana, R. C. F. Bonomo, O. R. R. Gandolfi, L. B. Rodrigues, L. S. Santos, A. C. d. S. Pires, C. P. de Oliveira, R. d. C. I. Fontan, and C. M. Veloso, J. Food Sci. Technol. 55, 278 (2018). https://doi.org/10.1007/s13197-017-2936-6

25. M. M. Rahman, F. E. Khan, R. Das, and M. A. Hossain, Int. Food Res. J. 23, 2399 (2016).

26. M. S. Moazzem, M. B. H. Sikder, and W. Zzaman, Beverages 5, 25 (2019). https://doi.org/10.3390/beverages5010025

27. X. M. Yang, W. Yu, Z. P. Ou, H. L. Ma, W. M. Liu, and X. L. Ji, Plant Foods Hum. Nutr. 64, 167 (2009). https://doi.org/10.1007/s11130-009-0120-5

28. M. Shafiq, S. Firdous, Q. Irfan, S. Khan, and A. Qadir, J. Sci. Res. 11, 365 (2019). https://doi.org/10.3329/jsr.v11i3.40493

29. M. Hossain, S. Parvin, S. Dutta, M. Mahbub, and M. Islam, J. Sci. Res. 8, 371 (2016). https://doi.org/10.3329/jsr.v8i3.26711

30. M. Shafiq, S. Mehmood, A. Yasmeen, S. J. Khan, N. H. Khan, and S. Ali, J. Sci. Res. 9, 135 (2017). https://doi.org/10.3329/jsr.v1i1.29665

31. Y. M. Tao, S. Wang, H. L. Luo, and W. W. Yan, Int. J. Biol. Macromol. 114, 898 (2018). https://doi.org/10.1016/j.ijbiomac.2018.04.007

32. Y. Zhang, Y. Zhang, F. Xu, G. Wu, and L. Tan, Sci. Rep. 7, 13423 (2017).

33. N. Affandi, W. Zzaman, T. A. Yang, and A. M. Easa, Beverages 3, 9 (2017). https://doi.org/10.3390/beverages3010009

34. H. S. Omar, H. A. El-Beshbishy, Z. Moussa, K. F. Taha, and A. N. Singab, Sci. World J. 11, 788 (2011). https://doi.org/10.1100/tsw.2011.71

35. W. Zzaman, R. Bhat, and T. A. Yang, J. Food Proces. Preserv. 38, 1932 (2014). https://doi.org/10.1111/jfpp.12166

36. K. Thaipong, U. Boonprakob, K. Crosby, L. Cisneros-Zevallos, and D. H. Byrne, J. Food Compos. Anal.19, 669 (2006). https://doi.org/10.1016/j.jfca.2006.01.003

37. K. Zhu, Y. Zhang, S. Nie, F. Xu, S. He, D. Gong, G. Wu, and L. Tan, Carbohydr. Polym. 155, 354 (2017). https://doi.org/10.1016/j.carbpol.2016.08.074

38. K. N. Prasad, F. A. Hassan, B. Yang, K. W. Kong, R. N. Ramanan, A. Azlan, and A. Ismail, Food Chem. 128, 1121 (2011). https://doi.org/10.1016/j.foodchem.2011.03.105

39. B. E. Richter, B. A. Jones, J. L. Ezzell, N. L. Porter, N. Avdalovic, and C. Pohl, Anal. Chem. 68, 1033 (1996). https://doi.org/10.1021/ac950910c

40. E. Kiassos, S. Mylonaki, D. P. Makris, and P. Kefalas, Innova. Food Sci. Emerg. Technol. 10, 246 (2009). https://doi.org/10.1016/j.ifset.2008.10.004

41. Y. M. Tao, L. Y. Yao, Q. Y. Qin, and W. Shen, J. Agric. Food Chem. 61, 12662 (2013). https://doi.org/10.1021/jf403828e

42. M. J. Rodriguez-Roque, B. de Ancos, R. Sanchez-Vega, C. Sanchez-Moreno, M. P. Cano, P. Elez-Martinez, and O. Martin-Belloso, Food Funct. 7, 380 (2016). 
https://doi.org/10.1039/C5FO01060H

43. S. Suh, Y. E. Kim, H. J. Yang, S. Ko, and G. P. Hong, Food Sci. Biotechnol. 26, 581 (2017). https://doi.org/10.1007/s10068-017-0085-3

44. V. Pavan, R. A. S. Sancho, and G. M. Pastore, LWT- Food Sci. Technol. 59, 1247 (2014). https://doi.org/10.1016/j.1wt.2014.05.040 